\title{
JOSÉ MARÍA ARGUEDAS, POETA Y MITÓGRAFO
}

\author{
MERCEDES LÓPEZ BARALT \\ Universidad de Puerto Rico (Puerto Rico) \\ mercedeslopezbaralt@gmail.com
}

\section{RESUMEN}

Hace unos años, y con su sabiduría habitual, Ernesto Sábato sentenció que «todos los filósofos y artistas, siempre que han querido alcanzar el absoluto, debieron recurrir a alguna forma del mito o de la poesía». José María Arguedas, heredero indiscutible del legado bicultural del Inca Garcilaso, es uno de ellos (de ahí que ambos sean los dos escritores emblemáticos del Perú). Hombre-puente entre dos culturas, dos lenguas y dos disciplinas (la andina y la occidental, el quechua y el castellano, la etnología y la literatura), el autor de Los ríos profundos es, ante todo, un poeta que, inmerso en la tradición oral del mundo andino, reescribe sus antiguos mitos para iluminar la peruanidad contemporánea. Examinaremos de cerca en este ensayo el rostro bifronte de Arguedas (poeta y mitógrafo) a partir del comentario textual de pasajes significativos de los diversos géneros que configuran su obra.

Palabras clave. José María Arguedas, poeta, mitógrafo, ensayo, cuento, novela.

\section{ABSTRACT}

Some years ago, Ernesto Sábato wisely stated that when philosophers and artists try to reach the imposible, they usually resort to myth or poetry. José María Arguedas, heir to the biculturality of the colonial Inca writer Garcilaso de la Vega, is one of them. As a bridge between two cultures (Andean and European), between two languages (Quechua and Spanish) and between two disciplines (ethnology and literature), the author of Los rios profundos is, above all, a poet who rewrites the ancient myths of the Andes to help the reader understand the complexities of his contemporary Peru. In this paper we aim to illuminate the particular blending of myth and poetry that characterizes his writing, through close reading of relevant moments of some of his novels, short stories, poems and translations.

Keywords. José María Arguedas, poet, tale, short stories, miths, translation.

Hace unos años, y con su sabiduría habitual, Ernesto Sábato sentenció que «todos los filósofos y artistas, siempre que han querido alcanzar el absoluto, debieron recurrir a alguna forma del mito o de la poesía» (2007, p. 58). José María Arguedas, heredero indiscutible del legado bicultural del Inca Garcilaso, es uno de ellos (de ahí que ambos sean los dos escritores emblemáticos del Perú). Hombre- puente entre dos culturas, dos lenguas y dos disciplinas (la andina y la occidental, el quechua y el castellano, la etnología y la literatura), el autor de Los ríos profundos es, ante todo, un poeta que, inmerso en la tradición oral del mundo andino, reescribe sus antiguos mitos para iluminar la peruanidad contemporánea. No importa el género que elija -la traducción, el ensayo etnológico, el cuento, la
Mercedes López-Baralt

Puertorriqueña. Tiene dos maestrías, una en literatura de la Universidad de Puerto Rico y otra en antropología, de Cornell, donde obtuvo su doctorado. También tiene un Doctorado Honoris Causa de la Universidad de Puero Rico, donde se desempeñó como catedrática y donde dirigió el Seminario Federico de Onís. Es autora de El mito taíno (1977), El retorno del Inca rey (1987), Icono y conquista: Guaman Poma de Ayala (1988), La gestación de Fortunata y Jacinta* (1992), Guaman Poma, autor y artista (1993), El barco en la botella: la poesía de Luis Palés Matos (1997), Sobre insulas extrañas: el clásico de Pedreira anotado por Tomás Blanco (2001), Para decir al otro: literatura y antropología en nuestra América (2005), Llévame alguna vez por entre flores (2006), Orfeo mulato: Palés ante el umbral de lo sagrado (2009), El Inca Garcilaso, traductor de culturas (2011) y Una visita a Macondo (manual para leer un mito) (2011). Autora de diversos ensayos y conferencias sobre el tema, actualmente prepara un libro titulado Miguel Hernández, poeta plural.
José María Arguedas, poeta y mitógrafo MERCEDES LÓPEZ BARALT 


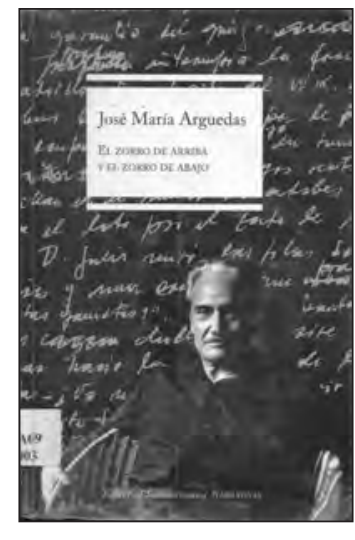

1

Lo afirmó en una conferencia publicada póstumamente, en la revista Bohemia (1970).
José María Arguedas, poeta y mitógrafo MERCEDES LÓPEZ BARALT novela o la poesía bilingüe-, la poesía y el mito (pilares de lo real maravilloso) configuran el ADN escritural de un autor que a partir de ambos construye las señas de identidad de la otredad que lo habita. A la vez, son el secreto del hechizo que ejerce sobre sus lectores, $y$ que lo ha catapultado a una fama sin fecha de caducidad. La razón es obvia: la poesía -que nace con el mito- constituye el más alto grado de la literariedad. Examinaremos de cerca en este ensayo el rostro bifronte de Arguedas (poeta y mitógrafo) a partir del comentario textual de pasajes significativos de los diversos géneros que configuran su obra.

En sus Cuadernos de Lanzarote (1970), decía José Saramago que vivimos para decirnos. Conviene recordar estas palabras al abordar la figura de Arguedas, pues si toda su obra gira en torno a la compleja identidad de su Perú, es porque en el fondo su autor se está preguntando constantemente quién es. $\mathrm{Su}$ historia de escritor es un fascinante relato de afirmaciones y renuncias. Habiendo reiterado en numerosas ocasiones que su lengua materna era el quechua, comienza y cierra su obra literaria narrando en castellano. Castellano que a su vez, no sólo se ve interrumpido constantemente por la lengua nativa, sino que, a medida que Arguedas va perfeccionando su oficio, se convierte en el vehículo sorprendente de los secretos del quechua. Alterna sus vocaciones de escritor y etnólogo; como lo ha visto John V. Murra (1996), cuando escribe no hace trabajo antropológico, y cuando se dedica a éste deja de escribir. Oscila entre su voluntad de compromiso político y la vocación contemplativa inherente a la escritura, entre la alegría de vivir y la tentación inescapable del suicidio. Y, siendo un poeta rotundo, sólo nos ha dejado un puñado de hermosos poemas bilingües de composición tardía.

Su publicación, en una antología de 1966, Temblar/Katatay, subraya la dualidad de la escritura arguediana. Dualidad cónsona con la complejidad étnica de un país en el que la geografía se convierte en tríada de sierra, costa y montaña. Lo que movió a Luis Alberto Sánchez a afirmar en 1939 que no hay un solo Perú, sino varios. Mariátegui ya había hablado -en sus Siete ensayos de interpretación de la realidad peruana (1928)- de la dualidad esencial de su país, nacida de la conquista del Perú autóctono por una raza extranjera que no ha podido fusionarse con la indígena. Arguedas, por su parte, declaraba en 1969 en La Habana que el hecho capital que decide el destino del Perú es la escisión del país en dos mundos totalmente distintos ${ }^{1}$.

Esta multiplicidad étnica, lingüística, cultural, ecológica y geográfica repercute, claro está, en la literatura. Pero casi siempre de manera parcial. Vargas Llosa, quien expresó su ambición totalizadora para la novela en García Márquez: Historia de un deicidio (1971), optó por dedicar distintas novelas a cada zona del Perú. Novelista costeño por excelencia (recordemos Los cachorros, Conversación en la catedral, La tía Julia y el escribidor, El elogio de la madrastra), incidió en el espacio de la selva con La casa verde, Pantaleón y las visitadoras y El hablador; y en el de la sierra, con Historia de Mayta y Lituma en los Andes. Aunque al comienzo de su carrera novelística, en La ciudad y los perros, quiso reunir las diversas zonas y etnias del Perú en el microcosmos limeño del Colegio Leoncio Prado.

Arguedas, sin embargo, vivió la diversidad desde dentro. Diversidad expresada a partir de la dualidad andina de hanan (alto) y burin (bajo), que según nos cuenta el Inca Garcilaso, dividió al Cuzco y al Tahuantinsuyo en dos espacios simétricos y a la vez jerarquizados, y que culmina literariamente, en la obra de nuestro autor, en su novela póstuma, El zorro de arriba y el zorro de abajo. Por llevar la otredad dentro de sí, su voz fue la más autorizada para poetizarla y novelarla. Bien lo comprendió Vargas Llosa; por ello le dedicó su libro La utopía arcaica: José María Arguedas $y$ las ficciones del indigenismo. En sus páginas liminares, tituladas "Una relación entrañable», el reciente Nobel explica que su fascinación con nuestro autor se debe a que «en un país escindido entre dos lenguas, dos culturas, dos tradiciones históricas, a él le fue dado conocer ambas realidades íntimamente, en sus miserias y grandezas, y, por lo tanto, tuvo una perspectiva mucho más amplia que la mía y que la de la mayor parte de los escritores peruanos sobre nuestro país» (1996, p. 9).

El autor de Los ríos profundos quiso, pues, novelar la diversidad. Novelarla, sí, pero sobre todo, poetizarla. Y es que estamos ante un gran poeta que optó por narrar. Lo confiesa el mismo Arguedas, a través del autor implícito que asoma en el niño narrador de la citada novela. Al hablar del canto de las calandrias, reconoce que «es seguramente, la materia de 
que estoy hecho» (1972, p. 158). No puede ser más explícita la afirmación de su condición de poeta. En la novela cantan los ríos, cantan las piedras, y el canto de los colonos -con el canto de Ernesto, que entona un carnaval de Pampachiri- logra atajar la epidemia de la fiebre que amenaza al colegio. Son muchas las manifestaciones que hace Arguedas de su vocación poética, siempre expresada en sentido metafórico, en alusiones a la música y al canto. Valga recordar otra, esta vez del segundo diario de El zorro de arriba y el zorro de abajo, en que al describir el vuelo de los patos de las lagunas de altura, dice que su imagen "convertía en música toda nuestra vida» (1990, p. 80). La música y el canto, casi siempre asociados a la tradición oral, mítica y ritual andina, son ubicuos en la prosa arguediana. Y se convierten en metáfora para la poesía. Ello puede inferirse del segundo diálogo entre los zorros, en la oposición entre la palabra y el canto. Según Arguedas, la palabra -instrumento del pensamiento racional- desmenuza al mundo, y al analizarlo, nos confunde. Por el contrario, el canto de los patos de altura, que hace bailar las flores de los abismos, ilumina el misterio, al hacernos «entender todo el ánimo del mundo» (1990, p. 46). El combate ritual entre logos y poesía estructura su novela póstuma. Se trata de las dos formas de pensamiento que caracterizan la naturaleza humana, y que Lévi-Strauss (1972) nombra como pensamiento domesticado o racional (que indaga en las relaciones de causa y efecto y se basa en la lógica y la diferencia) y pensamiento salvaje o espontáneo (que, basado en la semejanza, la transformación y la repetición, engendra tanto el mito como la poesía y el arte). No cabe duda de por cuál de las dos opciones se decidió el autor de Los zorros. Porque en la poesía encontramos al Arguedas más íntimo y auténtico. Pero esta poesía no se limita a sus versos, sino que arrasa -como sucede con el último gran indigenista, Manuel Scorza- con toda su obra.

Lo que podemos constatar al acercarnos a tres momentos de la más alta poesía arguediana, la que se da en su prosa; pasajes que abonan a la construcción de una identidad dual $^{2}$. El primero es la escena emblemática de Los ríos profundos:

\section{- ¡Zumbayllu, zumbayllu!}

Repetí muchas veces el nombre, mientras oía el

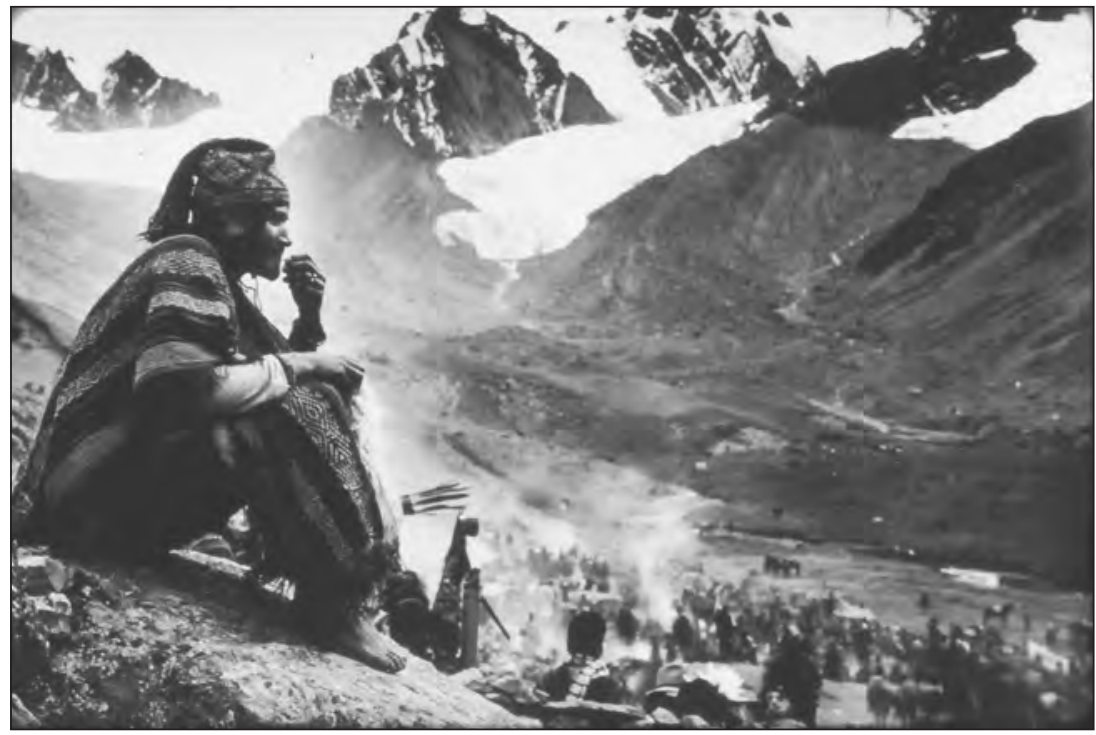

Imagen andina, Martín Chambi

zumbido del trompo. Era como un coro de grandes tankayllus fijos en un sitio, prisioneros sobre el polvo. Y causaba alegría repetir esta palabra, tan semejante al nombre de los dulces insectos que desaparecían cantando en la luz. [...]

El trompo se detuvo, un instante, en el aire y cayó después en un extremo del círculo formado por los alumnos, donde había sol. Sobre la tierra suelta, su larga púa trazó líneas redondas, se revolvió lanzando ráfagas de aire por sus cuatro ojos; vibró como un gran insecto cantador, luego se inclinó, volcándose sobre el eje. Una sombra gris aureolaba su cabeza giradora, un círculo negro lo partía por el centro de la esfera. Y su agudo canto brotaba de esa faja oscura. Eran los ojos del trompo, los cuatro ojos grandes que se hundían, como en un líquido, en la dura esfera. El polvo más fino se levantaba en círculo envolviendo al pequeño trompo.

El canto del zumbayllu se internaba en el oído, avivaba en la memoria la imagen de los ríos, de los árboles negros que cuelgan en las paredes de los abismos (1972, pp. 74-75).

No es difícil leer en esta cita una alegoría de la identidad peruana, construida lingüísticamente en la palabra dual que nombra al pequeño trompo, formada por una raíz castellana y un sufijo quechua. El narrador, en calidad de filólogo, ya había explicado las resonancias semánticas del sufijo onomatopéyico: «Yllu representa en una de sus formas la música que producen las pequeñas alas en vuelo; música que surge del movimiento de objetos leves» (1972, p. 70). Ya
2

Comenté por primera vez estos pasajes en el ensayo "La otredad puertas adentro: Arguedas y la construcción poética de la identidad» (2005).

José María Arguedas, poeta y mitógrafo MERCEDES LÓPEZ BARALT 


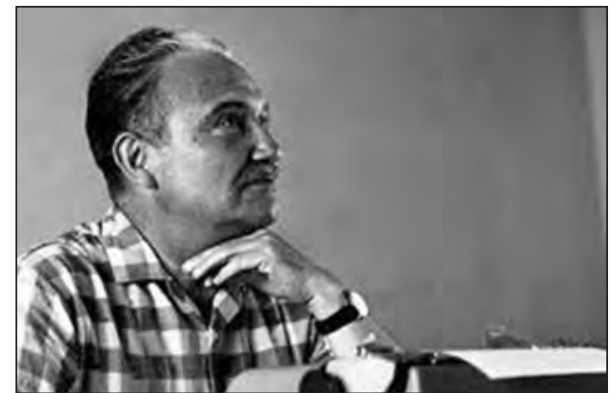

José María Arguedas

3

Así nombra Carlos Bousoño, en su Teoría de la expresión poética (1967), la imagen imposible del irracionalismo verbal que caracteriza a la vanguardia. La imagen ofrece dos variantes: aquella que otorga una calidad insólita a un sustantivo, o aquella que pone en pie de igualdad, aun siendo incompatibles, los dos planos de la comparación, el imaginario y el real.

José María Arguedas, poeta y mitógrafo MERCEDES LÓPEZ BARALT ante el trompo danzante, el narrador (que no es otro que el autor implícito) se torna poeta al saborear la belleza fónica del significante zumbayllu, que repite en voz alta una y otra vez. Pero sobre todo, se enfrenta al lenguaje desde una perspectiva mítica, en la que las palabras -contrario a lo que sugirió Michel Foucault en 1966 para la modernidad- sí son las cosas. En este caso, a partir de la onomatopeya. Inmerso en el pensamiento salvaje, el narrador da rienda suelta a la analogía, y convierte al zumbayllu en insecto que revolotea sin parar. Analogía que cede a la imagen visionaria ${ }^{3}$ o imposible: el insecto canta. Ahora bien, se trata de un canto mágico y ritual, inherente al sufijo $y l l u$, y que convoca su asociación con la voz pinkuyllu, quena gigante que tocan los indios del sur durante las fiestas comunales. El narrador nos había contado cómo esta quena sólo se toca en contextos rituales, y anima a los comuneros, quienes al oir su música desafían a la muerte, vencen toros salvajes, cavan túneles imposibles, danzan sin descanso. De ahí que el zumbayllu pueda comunicarse, a través de su canto, con el canto de los ríos y los árboles de los abismos andinos. No puede estar más claro: con este pasaje, el narrador, evidente alter ego del novelista Arguedas, emerge como poeta.

Otro momento de la alta poesía que tachonea de estrellas la prosa arguediana es la descripción del nionena en El zorro de arriba $y$ el zorro de abajo:

Sí; no hace quince días que logré rascar la cabeza de un nionena (chancho) algo grande, en San Miguel de Obrajillo. Medio que quiso huir, pero la dicha de la rascada lo hizo detenerse; empezó a gruñir con delicia, luego (¡cuánto me cuesta encontrar los términos necesarios!) se derrumbó a pocos y, ya echado y con los ojos cerrados gemía dulcemente. La alta, la altísima cascada que baja desde la inalcanzable cumbre de rocas, cantaba en el gemido de ese nionena, en sus cerdas duras que se convirtieron en suaves; y el sol tibio que había caldeado las piedras, mi pecho, cada hoja de los árboles y arbustos, caldeando de plenitud, de hermosura, incluso el rostro anguloso y enérgico de mi mujer, ese sol estaba mejor que en ninguna parte en el lenguaje del nionena, en su sueño delicioso (1990, pp. 8-9).
Este pasaje, uno de los más hermosos de Los zorros, figura en el primer diario de la novela, cuando Arguedas, asediado por la tentación del suicidio, siente otra vez la pulsión de la vida al acariciar al nionena. Y me recuerda la página final de Tristes trópicos, en la que Lévi-Strauss afirma que la libertad humana está precisamente en la obliteración de la oposición entre la naturaleza y la cultura, que se da fugazmente en los momentos en que aspiramos el aroma de un lirio, contemplamos la belleza iridescente de un mineral, o intercambiamos una mirada de perdón recíproco con un gato (1997, p. 468). En su diálogo silente con el nionena, Arguedas vuelve a insistir en su condición de poeta; más aún, de poeta simbolista, pues incide tanto en la imagen visionaria como en la sinestesia: el gemido del cerdo se convierte en canto que a su vez se convierte en sol.

El tercer pasaje que vale citar aquí es el diálogo de Arguedas con el pino de Arequipa de la misma novela, que tanto admiró Vargas Llosa en La utopía arcaica:

El pino de ciento veinte metros de altura que está en el patio de la Casa Reisser y Crioni, [...] ese pino llegó a ser mi mejor amigo. No es un simple decir. A dos metros de su tronco - es el único gigante de Arequipa -, a dos metros de su tronco poderoso, renegrido, se oye un ruido, el típico que brota a los pies de estos solitarios. [...] Desde cerca no se puede verle mucho su altura, sino sólo su majestad y oir ese ruido subterráneo, que aparentemente sólo yo percibía. Le hablé con respeto. Era algo para mí sumamente entrañable y a la vez de otra jerarquía [...] Oía su voz, que es la más profunda y cargada de sentido que nunca he escuchado en ninguna otra cosa ni en ninguna otra parte. Un árbol de éstos, como el eucalipto de Wayqoalfa de mi pueblo, sabe cuanto hay debajo de la tierra y en los cielos. Conoce la materia de los astros, de todos los tipos de raíces y aguas, insectos, aves y gusanos; y ese conocimiento se transmite directamente en el sonido que emite su tronco, pero muy cerca de él; lo transmite a manera de música, de sabiduría, de consuelo, de inmortalidad. Si te alejas un poco de estos inmensos solitarios ya es su imagen la que contiene todas esas verdades, su imagen completa, meciéndose con la lentitud que la carga del peso de su sabiduría y hermosura no le obliga sino que le imprime. Pero jamás, jamás de los jamases, había visto un árbol como éste y menos dentro de una ciudad importante. En los Andes del Perú los árboles son solitarios. En un patio de una residen- 
cia señorial convertida en casa de negocios, este pino, renegrido, el más alto que mis ojos han visto, me recibió con benevolencia y ternura. Derramó sobre mi cabeza feliz toda su sombra y su música. Música que ni los Bach, Vivaldi o Wagner pudieron hacer tan intensa y transparente de sabiduría, de amor, así tan oníricamente penetrante, de la materia de que todos estamos hechos y que al contacto de esta sombra se inquieta con punzante regocijo, con totalidad (1990, pp. 175-176).

Este conmovedor diálogo silente entre un hombre y un árbol pertenece al tercer diario de Los zorros. Arguedas pasa doce días en Arequipa, logra escribir quince páginas de la novela, y confiesa que «Por primera vez viví en un estado de integración feliz con mi mujer» (1990, p. 175). En su inolvidable diálogo con el pino, incide otra vez en la imagen visionaria: el árbol habla, emite música. El novelista-poeta, al extremar las posibilidades del pino, lo humaniza de tal modo que lo convierte en su mejor interlocutor: amigo sabio, que lo ampara y le ofrece el consuelo de la inmortalidad. Arguedas se hermana con el árbol porque ambos producen música, es decir, poesía: «la materia de que todos estamos hechos». Ha reiterado, casi verbatim, su afirmación de Los ríos profundos sobre el canto de las calandrias: "la materia de que estoy hecho». Pese a su generoso plural en el pasaje del pino, no cabe duda de que está hablando de su propia e intransferible condición de poeta. También de la esperanza. Como lo ha notado Gonzalo Portocarrero, el pasaje del trompo evoca un sentimiento utópico de comunión que destruye las jerarquías, creando un círculo presidido por el sol ${ }^{4}$. Lo mismo sucede en el del pino. Cabe advertir que los tres pasajes tienen el insólito denominador común de la alegría, tema al que volveremos en breve. Varias palabras apuntan a ello: regocijo, plenitud, sol, totalidad, hermosura, inmortalidad, delicioso, delicia, feliz, luz, canto y círculo, que es un emblema del infinito...

Hemos presentado tres hermosísimos pasajes dialógicos, marcados por la dualidad. En el primero, Arguedas celebra el abrazo de dos culturas en la palabra mestiza que nombra al trompo como zumbayllu. En el segundo y el tercero, el poeta oblitera la oposición entre naturaleza y cultura, al acariciar al cerdo y al hablarle al pino. Tanto el trompo, como el nionena y el árbol, responden cantando. Los tres pasajes proponen una identidad dual. El primero apunta - como toda la obra de Arguedas- a la construcción de la identidad peruana, fundada en el mestizaje de dos lenguas, dos etnias y dos culturas. El segundo y el tercero parecen proponer otra identidad, la del poeta que puede escuchar las voces de la naturaleza. Identidad tam-

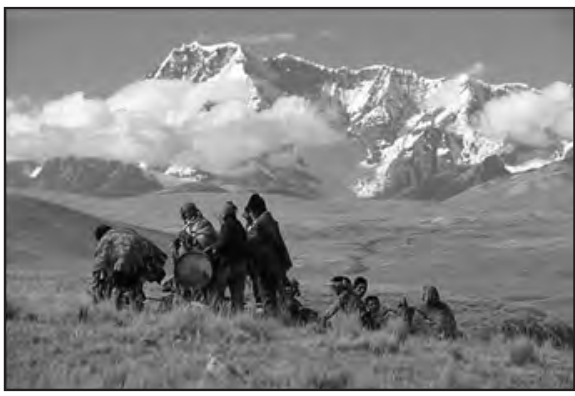

Paisaje andino bién dual, pues se trata de un novelista-poeta. Sin embargo, el primero no dista mucho de los demás, pues también propone la identidad irrenunciable de poeta que sustenta la obra de Arguedas, implícita en el canto del zumbayllu. A la vez, el diálogo con el nionena y con el pino expresan una comunión con la naturaleza que poco tiene que ver con la modernidad occidental, y mucho con el pensamiento mítico andino. Por otra parte, el trompo y el pino son expresión de la identidad peruana, mestiza: el primero se andiniza; mientras que el pino asume el gesto de don Felipe Maywa, el indio que protegía a Arguedas en su infancia, y que éste, desde su orfandad vulnerable, nombraba con el mismo adjetivo con el que califica al pino, "poderoso». Tomados en consideración los tres pasajes, podríamos leerlos como la propuesta de una identidad cifrada en el binomio poeta peruano, es decir, mestizo.

Poeta porque convierte en oro cuanto toca. Como los antiguos poemas quechuas que rescata del olvido, traduciéndolos de manera tan hermosa que por momentos pueden superar el original. Quisiera ofrecer dos ejemplos. El primero incide en el mito, pues tiene que ver con uno de los dos grandes héroes indígenas del imaginario peruano, Atahualpa (el otro es Tupac Amaru). Me refiero a la elegía anónima cuzqueña Apu Inka Atarvallpaman (A nuestro gran jefe Atahualpa), publicada por primera vez por José María Farfán en 1942, y que ha merecido transcripciones y traducciones sucesivas al castellano por Jesús Lara, José María Arguedas, Teodoro Meneses y la autora de estas líneas, en colaboración con Donald Solá. En mi caso quise, con mi recordado profesor de la Universidad de Cornell, bucear en los versos quechuas para ofrecer juntos una versión fiel al poema original. Pero en el fondo mi propósito estaba animado por el afán de descubrir de qué maneras Arguedas lo había mejorado, cosa que intuía por su alta condición de poeta. Así fue, y quisiera
Comunicación personal en la Casa de la Cultura de Lima, en ocasión del Seminario Internacional José María Arguedas y el Perú de hoy, organizado por Carmen María Pinilla y Gonzalo Portocarrero junto a otros estudiosos peruanos, y celebrado del 16 al 19 de agosto de 2004 .

José María Arguedas, poeta y mitógrafo MERCEDES LÓPEZ BARALT 
5 Aquí cito a Lara por la edición de Meneses (1957, p. 36).

6 En «La otredad puertas adentro: Arguedas y la construcción poética de la identidad» (2005).

José María Arguedas, poeta y mitógrafo MERCEDES LÓPEZ BARALT demostrarlo aquí a partir del examen de dos estrofas del poema. Y ello pese a que nuestro autor advierte, en su edición de la elegía, que la traducción «ha sido hecha verso a verso, imagen por imagen, metáfora por metáfora, sin inventar ni agregar nada» $(1955$, p. 8). Veamos si es verdad.

Y comenzamos con la segunda estrofa de la elegía, cuyo texto original lee: «Watupakurkan sunqollaymi / sapakutin / musqoynipipas - ccheqmi ccheqmi, / uti uti, - / chiririnka qhenchataraqmi, / aqoy phuti» (1955, p. 11). Arguedas lo traduce así: «Mi corazón presentía / a cada instante, / aun en mis sueños, asaltándome, / en el letargo, / a la mosca azul anunciadora de la muerte; / dolor inacabable» $(1955$, p. 10). Nuestro autor ha hermoseado la traducción nombrando el color azul, que no está presente en el nombre de la mosca, chiririnka, y que resulta poético por sus connotaciones darianas y por su alusión oblicua al infinito a partir de dos metáforas clásicas (mar y cielo). Chiririnka qhenchataraqmi quiere decir, literalmente, «la mosca de mal agüero», pero Arguedas prefirió sustituir «de mal agüero» por una frase ominosa, logrando un sintagma poderoso que sugiere lo inexorable: «la mosca azul anunciadora de la muerte». Con gran tino, y para no trivializar la estrofa, ha eliminado el diminutivo afectivo de corazón, implícito en el sufijo -lla, que nos obligaría a traducir sunqollaymi como mi corazoncito.

Aquí el texto quechua de la estrofa XVIII: «Thukuruyanñan sirkkaykipi / yawarniyki; / qhoqayarinñan ñawiykipi / rikuyniyki; / ancha qoyllur lliphlliynillanpi / qhawayniyki» (1955, p. 19). Arguedas lo traduce como sigue: «Se ha acabado ya en tus venas / la sangre; /se ha apagado en tus ojos / la luz;/ en el fondo de la más intensa estrella ha caído / tu mirar» (1955, p. 18). Una traducción literal de la estrofa diría así: «Ya se acaba en tus venas/ tu sangre,/ ya comienza a palidecer en tus ojos/ tu mirar,/con su brillo de intensa estrella/ tu mirada». Respetando el original quechua, Arguedas no repite la palabra mirar, para la cual son sinónimos rikuy y qhaway. Pero al sustituirla por $\operatorname{lnz}$ en el cuarto verso, mejora la estrofa al prepararle el camino a la palabra estrella (qoyllur). También añade frases que no están en el original: en el fondo de y ha caído, frases que no recogen ni Farfán, ni Meneses, ni López-Baralt con Solá. Su afán de embellecer el original tiene en este caso un precedente, el de Jesús Lara, que dice: «En el brillo de alguna estrella está escondida/ tu mirada» ${ }^{5}$. Con mayor vuelo en el verso, Arguedas dirá: «en el fondo de la más intensa estrella/ha caído tu mirar».

El segundo ejemplo de traducción poética que quiero examinar es el de un huayno quechua recogido por Arguedas en el Perú (1946, p. 26), y sobre el que he escrito en otra ocasión $^{6}$ :

Hoy es el día de mi partida.

Hoy no me iré, me iré mañana.

Me veréis salir tocando una flauta de hueso de mosca, llevando por bandera una tela de araña.

Será mi tambor un huevo de hormiga.

¿Y mi montera?

Mi montera será un nido de picaflor.

Este huayno tradicional andino, del que Arguedas no nos ofrece el original en quechua, bien puede leerse como un digno epitafio para nuestro autor. Por muchas razones. Primero, porque nos enfrenta con el rol imprescindible de Arguedas, el de traductor. No sólo de la lengua quechua, sino de todo un mundo. En segundo lugar, porque el huayno original es una composición anónima y oral, en quechua, que rescata en su carácter de etnólogo. En tercer lugar, porque se trata de un espléndido poema. Y Arguedas, como poeta, lo sabía.

Al traducir el huayno, nuestro autor lo tituló «Despedida». Como diría Machado en una de sus canciones a Guiomar, "Se canta lo que se pierde» (2009, p. 376). Arguedas, poeta ante todo, no pudo menos que entender que en las alucinantes metáforas del poema, que hoy podemos hacer nuestras como surrealistas, la muerte es omnipresente: la flauta de hueso de mosca y el tambor de huevo de hormiga sólo pueden producir silencio; el minúsculo nido de picaflor es tan sólo paja vacía. La bandera de tela de araña es nada, puro agujero. Silencio, nada y vacío. Y sin embargo, en el poema late un optimismo feroz, como el que Arguedas abrazó, contra todo y porque sí, toda su vida. El sujeto lírico, cual el Miguel Hernández que dijera en El rayo que no cesa, «Me voy, me voy, me voy pero me quedo,/ pero me voy...» (1992, I, p. 504), sabiendo que la partida es inexorable, se toma la libertad de retrasarla. Pero también la de asumirla como 
marcha triunfal. Un detalle del poema nos permite leerlo como expresión desafiante de una identidad colectiva amenazada: la alusión a la bandera. He emprendido esta lectura del huayno -moderna y occidentalizada, lo admito- porque me parece emblemático de dos pulsiones encontradas de Arguedas: un optimismo voluntarioso que lo mueve a preservar un mundo que se le derrumba de a poco, y la decisión del suicidio como salida digna a una depresión que el psicoanálisis de aquel momento no pudo curar.

Faltando el original en quechua, no podemos calibrar si se trata de una traducción literal, aunque la lectura de su versión castellana de Apu Inka Atawallpaman me hace sospechar que podría tratarse de una traducción creativa, libre. Hace años me inclinaba a pensar que las metáforas surrealistas pudieran ser de la cosecha de Arguedas, hasta que un admirado colega, Alfredo Alberdi Vallejo, me enviara una variante del huayno, procedente de la tradición oral de Huamanga, según lo oyó de labios de su bisabuela. Cito aquí, en español y en quechua, el huayno huamanguino titulado Ripuy (Márchate), que nos permite constatar la autoctonía andina de dos de las metáforas del huayno arguediano, las que aluden al tambor y a la flauta:

$\begin{array}{ll}\begin{array}{l}\text { Ripuy, ripuy } \\ \text { niwachkanki, }\end{array} & \text { Márchate, ándate } \\ \text { pasay, pasay, } & \text { me estás ordenando (diciendo) } \\ \text { niwachkanki, } & \text { me estás ordenando (diciendo) } \\ \text { manaraq } & \text { incluso antes } \\ \text { ripuypas } & \text { que el viaje } \\ \text { kallachkaptin } & \text { haya llegado, } \\ \text { manaraq } & \text { incluso antes } \\ \text { pasaypas } & \text { que la partida } \\ \text { kallachkaptin. } & \text { haya llegado. } \\ \text { Ripuytaqa } & \text { Al irme } \\ \text { ripusaqmi } & \text { me iré, } \\ \text { pasaytaqa } & \text { al apartarme } \\ \text { pasasaqmi, } & \text { me apartaré, } \\ \text { wanwapa tulluchan } & \text { haciendo de los huesos del zancudo } \\ \text { kenaschayoq, } & \text { una quenita, } \\ \text { arañapa llikachan } & \text { haciendo de la telarañita } \\ \text { tamborchayoq. } & \text { un tamborcito. } \\ & \text { (2007, p. 2) }\end{array}$

Alberdi Vallejo -que como respuesta a mis preguntas sobre «Despedida», publicó este huayno en el diario de Huamanga La Voz, en un ensayo titulado «La palabra empeña-

da»-afirma que no se conoce la fuente quechua del huayno traducido por Arguedas. Por lo que queda en suspenso la incógnita de si el autor de Los ríos profundos recreó o no el texto original.

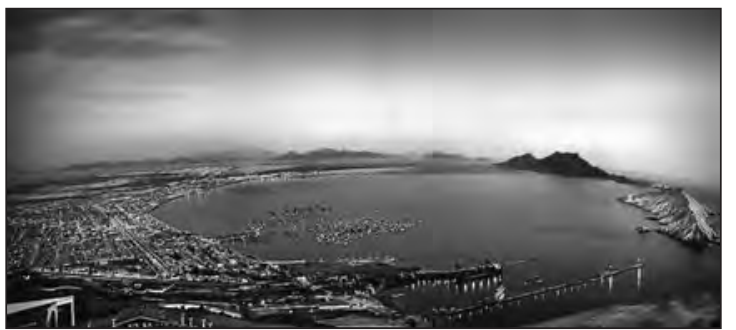

Panorámica de Chimbote
Pero de lo que no ca-

be duda es que su traducción constituye, por sí sola, un poema magistral.

Nos hemos ocupado hasta aquí de la poesía, pero no podemos olvidar que ésta nació con el mito. Y el mito es omnipresente en la obra arguediana. Porque el autor de Los ríos profundos recoge, traduce y publica mitos (el de Inkarrí, los de Huarochirí) y reescribe mitos (estos últimos, en su novela póstuma). Pero nuestro autor también es mitógrafo, o creador de mitos. A partir de la noción ancestral andina de wakcha o huérfano ${ }^{7}$, convierte en héroes míticos a varios de los personajes de sus novelas, incluyendo a su propia persona. El mismo Arguedas da su definición antropológica del término:

Los indios [...] dividen a la gente en dos categorías. La categoría de los que poseen bienes, ya sea en terrenos o animales, es gente, pero el que no tiene ni animales es buak'cho. La traducción que se le da a este término al castellano es huérfano. Es el término más próximo porque la orfandad tiene una condición no solamente de pobreza de bienes materiales sino que también indica un estado de ánimo, de soledad, de abandono, de no tener a quién acudir. Un huérfano, un buak'cho, es aquél que no tiene nada. Está sentimentalmente lleno de gran soledad y da gran compasión a los demás (1982, pp. 106-107)8.

La marginalidad andina, resultado nefasto de la conquista española, convirtió en legión a los indígenas desposeídos, forasteros, huérfanos sociales arrancados de su centro de gravedad: el ayllu o comunidad étnica basada en el parentesco. $\mathrm{Y}$ la literatura peruana dio fe del hecho, al elevar a categoría protagónica al wakcha, desde que Guaman Poma iniciara el último capítulo de su Nueva coronica $i$ buen gobierno con el sugestivo título de «Camina el autor». Empobrecido y desterrado de su ciudad de Huamanga, como forastero vaga el autor andino hacia Lima para entregar su manuscrito de agravios a las autoridades virreinales. Su peregrinación lo convierte en
7

En «Wakcha, pachakuti y tinku: tres llaves andinas para acceder a la escritura de Arguedas» (1996, pp.298-330) y «Sobre los caminos de regreso a la arcadia original: el indigenismo de José María Arguedas» (2005, pp.317-344), estudio esta noción andina, ligada a las otras mencionadas en el título del primer ensayo, y que comentaremos en breve.

8

Testimonio de Arguedas grabado por Sara Castro-Klarén y recogido por Julio Ortega en Texto, comunicación y cultura: Los ríos profundos de José María Arguedas.
José María Arguedas, poeta y mitógrafo MERCEDES LÓPEZ BARALT 
antecedente de los migrantes serranos de hoy, que invaden Lima con su economía paralela, sus tradiciones, sus clubs y su poesía urbana, a la que Julio Noriega le ha dedicado un libro importante: Poesía quechua escrita en el Perú. Antología. El migrante andino, huérfano errante que deviene en el sujeto de su propia poesía, tiene antecedentes prehispánicos en los mitos de Huarochirí, en los que Viracocha y Pariacaca figuran como dioses pobres y peregrinos.

Arguedas se inserta en esta larga tradición, pues en su obra el wakcha se multiplica en personajes como Ernesto, la opa Marcelina y la chichera Felipa de Los ríos profundos; en el protagonista niño del cuento «Warma kuyay»; y en la mestiza Fidela de Los zorros. Que nuestro autor se ve a sí mismo como huérfano andino se desprende de su famosa intervención en el Primer Encuentro de Narradores Peruanos en Arequipa en 1965:

Voy a hacerles una confesión un poco curiosa: yo soy hechura de mi madrastra. Mi madre murió cuando yo tenía dos años y medio. Mi padre se casó en segundas nupcias con una mujer que tenía tres hijos; yo era el menor y como era muy pequeño me dejó en la casa de mi madrastra, que era dueña de la mitad del pueblo; tenía mucha servidumbre indígena y el tradicional menosprecio e ignorancia de lo que era un indio, y como a mí me tenía tanto rencor como a los indios, decidió que yo había de vivir con ellos en la cocina, comer y dormir allí. Mi cama fue una batea de ésas en que se amasa harina para hacer pan, que todos conocemos. Sobre unos pellejos y con una frazada un poco sucia, pero bien abrigadora, pasaba las noches conversando y viviendo tan bien que si mi madrastra lo hubiera sabido me habría llevado a su lado, donde sí me hubiera atormentado (1969, p. 36).

Sabido es que Arguedas proyectó su condición biográfica de huérfano a su condición cultural de marginado de ambos mundos, el andino y el occidental. Es interesante notar cómo, cuando comienza su trabajo psicoanalítico con la Dra. Lola Hoffmann en Santiago de Chile, la llama madre y le escribe en quechua. Aunque la carta lleva su traducción al español, el gesto es claro: el huérfano es un wakcha, aquel niño que solo halló consuelo en la cocina de la hacienda, con sus sucesivas madres indias. Cito, de la edición de Las cartas de Arguedas que publiqué con John V. Murra en 1996, una carta de abril de 1962:

Hatun mamay Lola:

Paqarinmi ripukusaq makiykipa chaninchasqa, ñakariy qochamanta qespisqa.

Mana chanin munaykiwan, pacha tutayaypa sonqonman chayaq ñawikiwan, muchuq kuyaq hatun mamay, qespichiwanki. Manan qonqasqaykichu, qanpa, B. sutinpin allin qari hina llankasaq, hatun mamay. Gabypas sumaqta yanapawan, kirisqa wayqenta hina, qan rayku.

Kutimusqaykin «Jonastan» apumusqayki, Beatrispa, ñoqa sutinpi makikipa churaykusaq. Peruniypa sutinpi.

\section{(Mi gran madre Lola:}

Me voy mañana, fortalecido por tus manos, de los mares del dolor casi salvado.

Con tus manos invalorables, con tus ojos que penetran la más oscura sombra del mundo, gran madre que amas a los que sufren, me has levantado. No he de olvidarte. En tu nombre y en el de Beatriz trabajaré como un mozo renovado. También Gaby estuvo a mi lado, como ante un hermano herido.

He de volver. Te traeré «Jonás», lo pondré en tus manos, a nombre de B. [tachadura], a mi nombre y el de mi patria.)

José María

(1996, pp. 72-73).

En su himno a Tupac Amaru -Tupac Amaru kamaq taytanchisman- Arguedas también se declara huérfano, desde la misma dedicatoria del poema: «A Doña Cayetana, mi madre india, que me protegió con sus lágrimas y su ternura, cuando yo era un niño huérfano alojado en una casa hostil y ajena» (1983, p. 225). Pero la carencia vital que convierte a Arguedas en un huérfano mítico engendra una paradoja de luz y sombra. Al desdeñarlo su madrastra, relegándolo a la cocina de la casa de su hacienda, no hizo otra cosa que regalarle, malgré lui, más que padres y madres indígenas que lo llenaron del amor que le faltaba, otra lengua, otra cultura. El dolor le multiplicó el alma, convirtiéndolo en puente entre dos mundos, y llevándolo, paradójicamente, a la esperanza, como se desprende de la parte final de la dedicatoria del himno a Tupac Amaru: «A los comuneros de los cuatro ayllus de Puquio en quienes sentí por primera 
vez la esperanza» (1983, p. 225). Este himno bilingüe a la figura del último líder de la resistencia incaica supone el esfuerzo de nuestro autor por elevarlo a la misma estatura mítica de Atahualpa, quien había merecido la ya citada elegía anónima cuzqueña por su muerte y el tan difundido mito oral de Inkarrí9. En sus versos late la esperanza del pachakuti, la noción mesiánica andina del mundo al revés que ha de garantizar el regreso del Inca rey. Cito un fragmento de la versión española del poema en el que Arguedas enarbola la bandera de la esperanza:

Tranquilo espera, tranquilo oye, tranquilo contempla este mundo.

Estoy bien jalzándome!

Canto;

bailo la misma danza que danzabas

el mismo canto entono.

Aprendo ya la lengua de Castilla, entiendo la rueda y la máquina; con nosotros crece tu nombre; hijos de wiraqochas te hablan y te escuchan como al guerrero maestro, fuego puro que enardece, iluminando.

Viene la aurora.

Me cuentan que en otros pueblos

los hombres azotados, los que sufrían, son ahora águilas, cóndores de inmenso y libre vuelo.

Tranquilo espera.

Llegaremos más lejos de cuanto tú quisiste y soñaste. Odiaremos más que cuanto tú odiaste;

amaremos más de lo que tú amaste, con amor de paloma encantada, de calandria.

Tranquilo espera, con ese odio y ese amor sin sosiego y sin límites, lo que tú no pudiste hacer lo haremos nosotros.

Al helado lago que duerme, al negro precipicio, a la mosca azul que ve y anuncia la muerte a la luna, las estrellas y la tierra, al suave y poderoso corazón del hombre; a todo ser viviente y no viviente, que está en el mundo, en el que alienta o no alienta la sangre, hombre o paloma, piedra o arena, haremos que se regocijen, que tengan luz infinita, Amaru, padre mío.

La santa muerte vendrá sola, ya no lanzada con hondas trenzadas ni estallada por el rayo de pólvora. El mundo será el hombre, el hombre el mundo, todo a tu medida (1983, pp. 231-233).

Si el dolor de la orfandad llevó a Arguedas a la esperanza, también lo llevó a la alegría.
Porque lo tornó en metáfora viva de aquel ancestral tinku que, desde el pensamiento mítico, esencializa a la cultura andina. Franklin Pease definió hace años esta noción milenaria como el encuentro ritual, conflictivo, de dos mitades -hanan y burin- que componen la compleja totalidad ${ }^{10}$, ya sea ésta el Tahuantinsuyo, el Cuzco, o cualquier comunidad indígena andina. Pero en un sentido amplio el tinku alude a la dimensión conflictiva que funda la peruanidad: sierra versus costa, quechua versus español, cultura andina versus cultura hispánica, antigüedad versus modernidad. Arguedas lo sabe, y en un momento triunfal de Los ríos profundos celebrará la abundancia de horizontes que le otorga su identidad dual con brío lírico, metaforizando la ambición inclusiva de su amor con dos imágenes libertarias: el puente y el río. Ansía ser como ambos, pero termina eligiendo a éste, porque su perpetuo movimiento logra el milagro de llevar la sierra hasta el mar. Y ese río no es otro que él mismo: «Yo no sabía si amaba más al puente o al río. [...] Debía ser como el gran río: cruzar la tierra, cortar las rocas; pasar, indetenible y tranquilo, entre los bosques y montañas; y entrar al mar, acompañado por un gran pueblo de aves que cantan desde la altura» (1972, p. 68).

La serpiente se muerde la cola, y volvemos al canto. El canto, denominador común de los pasajes poéticos ya comentados de su prosa, es la forma primigenia de la poesía, fundada en la música, la metáfora y la sinestesia; y a la vez, la expresión más alta de la alegría de este poeta tan desgarrado que es Arguedas. Canto no sólo literario, sino etnológico y a la vez personal. Poco antes de morir, en 1969, Arguedas publicó un disco ${ }^{11}$ en el que leía El sueño del pongo, y en el que también cantaba, con alegría rotunda, canciones quechuas tradicionales: la trilla de la arbeja y un carnaval de Tambobamba. Alegría que late agazapada en el inolvidable huayno -género musical bailable, no lo olvidemos- que tituló «Despedida». Alegría que defendió Arguedas, anticipando a Benedetti, en carta a Alejandro Ortiz Rescaniere el último año de su vida, y cuyo pasaje más conmovedor citó Vargas Llosa en La utopía arcaica: « $i \mathrm{Si}$ te imaginaras cuán enfermo irremediable condenado creí ser durante toda la infancia y la adolescencia! Pero nadie ha sido más feliz que yo. Nadie, ni tú» (1996, p. 288). Y alegría que nos mueve a recordarlo con
9

He dedicado un libro al tema: El retorno del Inca rey: mito y profecía en el mundo andino (1987).

10

Comunicación personal reiterada entre los años ochenta y noventa.

11

Publicado por la Editorial Universitaria de Santiago de Chile.
José María Arguedas, poeta y mitógrafo MERCEDES LÓPEZ BARALT 
Así titula Carmen María Pinilla su impresionante antología de la obra arguediana.
José María Arguedas, poeta y mitógrafo MERCEDES LÓPEZ BARALT unos versos de otro poeta, esta vez español. Me refiero a Pepe Hierro. En uno de sus primeros libros, titulado precisamente Alegría, y recordando nada menos que a un pino cuya belleza-como en el caso del de Arequipa- le hace intuir la inmortalidad, Hierro desafió, como Arguedas, la precariedad de la vida con las porfiadas palabras de la poesía:

$$
\begin{aligned}
& \text { Pero yo, que he tocado una vez las agudas } \\
& \text { agujas del pino, } \\
& \text { no podré morir nunca. [...] } \\
& \text { Aunque muera mi cuerpo, y no quede } \\
& \quad \text { memoria de mí } \quad \text { (1962, p. 118). }
\end{aligned}
$$

Arguedas lo proclamaría en quechua: $; \mathrm{Ka}$ chkaniraqmi!12. Es decir: ¡Sigo siendo!

\section{Bibliografía}

Alberdi Vallejo, Alfredo (2007), «Recortes andinos/ La palabra empeñada», $L a v o z$ de Huamanga, 13: 4, 018, 24 de enero, p. 2.

Arguedas, José María (1990), El zorro de arriba y el zorro de abajo, Madrid, Unesco, Colección Archivos/ Ministerios de Cultura de España y Francia.

Arguedas, José María (2004), ¡Kachkaniraqmi! ¡Sigo siendo! Textos esenciales, Carmen María Pinilla (ed.), Lima, Fondo Editorial del Congreso del Perú.

Arguedas, José María (1970), «La literatura peruana», La Habana, Bohemia.

Arguedas, José María (1972), Los ríos profundos, Buenos Aires, Losada.

Arguedas, José María (1983), Obras completas. Lima, Horizonte, volumen quinto.

Arguedas, José María (1965), Temblar. El sueño del pongo/Katatay. Pongoq mosqoynin. Lima, Salqantay.

Arguedas, José María (ed.) (1955), Apu Inka Atawallpaman, Lima, Juan Mejía Baca y P.L. Villanueva Editores, pp. 4-23.

Arguedas, José María (ed.) (1946), Canciones y cuentos del pueblo quechua, Lima, Huascarán.

Arguedas, José María (ed.) (1966), Dioses y hombres de Huarochirí, México/España/ Argentina, Siglo Veintiuno.

Arguedas, José María (ed.) (1996), Las cartas de Arguedas, John V. Murra y Mercedes López-Baralt (eds.), Lima, Pontificia Universidad Católica del Perú.

Arguedas, José María/Josafat Roel Pineda (1973), «Tres versiones del mito de Inka- rrí», en Juan M. Ossio A. (ed.), Ideología mesiánica del mundo andino, Lima, Ignacio Prado Pastor, pp. 219-225.

Arguedas, José María, et al. (1969), Primer encuentro de narradores peruanos (Arequipa, 1965), Lima, Casa de la Cultura.

Bousoño, Carlos (1967), Teoría de la expresión poética, Madrid, Gredos.

Farfán, José María (ed.) (1942), «Poesía folklórica quechua», Revista del Instituto de Antropología de la Universidad Nacional de Tucumán, 2: 12, pp. 543-546.

Foucault, Michel (1966), Les mots et les choses, Paris, Gallimard.

Guaman Poma de Ayala, Felipe (1980), Nueva coronica $i$ buen gobierno, John V. Murra y Rolena Adorno (eds.), México, Siglo XXI.

Hernández, Miguel (1992), Obra completa, Poesía (volumen I), edición de Agustín Sánchez Vidal y José Carlos Rovira, con la colaboración de Carmen Alemany, Madrid, Espasa Calpe.

Hierro, José (1962), Poesías completas (19441962), Madrid, Giner.

Lara, Jesús (1947), La poesía quechua, México, Fondo de Cultura Económica.

Lévi-Strauss, Claude (1972), El pensamiento salvaje, México, Fondo de Cultura Económica.

Lévi-Strauss, Claude (1997), Tristes trópicos, Buenos Aires, Paidós.

López-Baralt, Mercedes (1987), El retorno del Inca rey: mito y profecía en el mundo andino, Madrid, Playor.

López-Baralt, Mercedes (2005), «La otredad puertas adentro: Arguedas y la construcción poética de la identidad», en Carmen Pinilla (ed.), Arguedas y el Perú de boy, Lima, Sur: Casa de Estudios del Socialismo, pp. 355-362.

López-Baralt, Mercedes (2005), Sobre los caminos de regreso a la arcadia original: el indigenismo de José María Arguedas», en Mercedes López-Baralt, Para decir al Otro: literatura y antropología en nuestra América, Madrid, Iberoamericana Vervuert, pp. 317-344.

López-Baralt, Mercedes (1996), «Wakcha, pachakuti y tinku: tres llaves andinas para acceder a la escritura de Arguedas», en John V. Murra y Mercedes López-Baralt (eds.), Las cartas de Arguedas, Lima, Pontificia Universidad Católica del Perú, pp. 298-330. 
López-Baralt, Mercedes y Donald Solá (1980), «The Quechua Elegy to the All-Powerful Inka Atawallpa: A Literary Rendition of the Inkarrí Myth», Latin American Indian Literatures, Pittsburgh, 4: 2, pp. 79-86.

Machado, Antonio (2009), Poesías completas, Manuel Alvar (ed.), Madrid, Austral.

Mariátegui, José Carlos (1970), Siete ensayos de interpretación de la realidad peruana, Lima, Amauta.

Meneses, Teodoro L. (ed.) (1957), Apu Inqa Atabuallpaman. Elegía quechua de autor cuzqueño desconocido, Lima, Publicaciones del Instituto de Filología de la Facultad de Letras de la Universidad de San Marcos, Textos Universitarios, $\mathrm{n}^{\circ} .15$.

Murra, John V. (1966) «Semblanza de Arguedas», en John V. Murra y Mercedes López-Baralt (eds.), Las cartas de Arguedas, Lima, Pontificia Universidad Católica del Perú, pp. 283-298.

Noriega Bermuy, Julio (1993), Poesía quechua escrita en el Perú. Antología, Lima, Centro de Estudios y Publicaciones.

Ortega, Julio (1982), Texto, comunicación y cultura: Los ríos profundos de José María
Arguedas, Lima, Centro de Estudios para el Desarrollo y la Participación.

Pease G. I., Franklin (1973), «El mito de Inkarrí y la visión de los vencidos», en Juan Ossio (ed.), Ideología mesiánica del mundo andino, Lima, Ignacio Prado Pastor, pp. 439-452.

Pinilla, Carmen María (1994), Arguedas: conocimiento y vida, Lima, Pontificia Universidad Católica del Perú, Fondo Editorial.

Sábato, Ernesto (2007), La resistencia, Buenos Aires, Seix Barral.

Sánchez, Luis Alberto (1939), La literatura de Perú, Universidad de Buenos Aires.

Saramago, José (1997), Cuadernos de Lanzarote, Alfaguara España.

Vargas Llosa, Mario (1971), García Márquez: Historia de un deicidio, Barcelona, Barral. Vargas Llosa, Mario (1996), La utopía arcaica: José María Arguedas y las ficciones del indigenismo, México, Fondo de Cultura Económica.

Fecha de recepción: 07/07/2012

Fecha de aceptación: 22/10/2012 